\title{
“DA DONA QUE RESULTOU SERE BONECA": O EPISÓDIO DO XARDÍN DOS ANDRADA E OS CORPOS IMPRÓPRIOS NA NARRATIVA DE A ESMORGA
}

\section{“THE LADY WHO HAPPENED TO BE A DOLL": THE EPISODE OF THE ANDRADA'S GARDEN AND THE NOT PROPER BODIES IN THE NARRATIVE OF A ESMORGA}

\author{
Fernanda Gappo Lacombe ${ }^{1}$ \\ Universidade Federal Fluminense
}

\begin{abstract}
Resumo: O presente artigo tem por objetivo principal analisar o papel dos corpos impróprios dentro de A Esmorga, de Eduardo Blanco Amor, a partir do episódio do Xardín dos Andrada. Para tal, serão apresentadas as definições de Silvia Federici (2017) de corpos indisciplinados, assim como o conceito de "the self's clean and proper body" de Margritt Shildrick (2002). Também será utilizado a definição de homossexualidade marginal de Alberto Mira (2007), com o objetivo de relacionar as ideias de corpos fora da norma, apresentadas por Federici (2017) e Shildrick (2002), com a personagem de Milhomes, de modo que, ao final deste trabalho, seja possível perceber, não somente a crítica à lógica homofóbica da sociedade galega e espanhola, que Blanco Amor, ironicamente, apresenta no romance, como também, a importância do episódio do Xardín pelo paralelo que estabelece com os desejos reprimidos de Bocas por Milhomes.
\end{abstract}

Palavras-chave: Literatura galega; Neorrealismo; Eduardo Blanco Amor; Corpo; Homossexualidade.

\footnotetext{
${ }^{1}$ gappolacombe@gmail.com
} 
Abstract: The main objective of this article is to analyze the role of inappropriate bodies within A esmorga, by Eduardo Blanco Amor, from the Xardin dos Andrada episode. To this end, Silvia Federici's definitions (2017) of body disciplining will be presented, as well as the concept from "the self's clean and proper body" by Margritt Shildrick (2002). Alberto Mira's definition (2007) of marginal homosexuality will also be used, in order to relate the ideas of bodies outside the norm, presented by Federici (2017) and Shildrick (2002), with the character of Milhomes, so that, at the end of this work, it is possible to perceive, not only criticizing the homophobic logic of Galician and Spanish society, which Blanco Amor, ironically, presents in the novel, but also the importance of the Xardin episode due to the parallel it establishes with the repressed desires of Bocas by Milhomes.

Keywords: Galician literatura; Neorealism; Eduardo Blanco Amor; Body; Homosexuality.

\section{INTRODUÇÃO}

Em 1959, após alguns anos sem publicar uma obra literária em galego, o poeta, narrador, ensaísta e intelectual galeguista, Eduardo Blanco Amor, lança, em Buenos Aires, o que é considerado um romance de renovação da narrativa galega, renovação esta, que não chega sem causar alvoroço.

Segundo Álex Alonso Nogueira (2009), não apenas a censura franquista se colocava como impeditivo para o lançamento da obra na terra natal do autor, mas também a resistência de um campo ideológico dentro do próprio Editorial Galaxia. Citando Nogueira (2009):

Unha carta enviada por Ramón Piñeiro a Fernández del Riego en marzo dese mesmo ano revela que esta distancia implicaba algo máis, unha tensión en certo sentido de campo, que afectaba ao papel que se lle outorgaba á literatura e máis en xeral á cultura gallega durante os anos cincuenta, senón unha interpretación ben diferente do que era esa mesma cultura. (NOGUEIRA, 2009, p. 28)

Ainda segundo Nogueira (2009), esta tensão entre dos campos se manifesta em três aspectos: primeiro, na escolha de Blanco Amor por retratar com uma crueza brutal a vida do proletariado das cidades galegas, em uma atmosfera de opressão, decadência e escassez, que se aproxima mais do neorrealismo italiano e do realismo social espanhol do que da linha hegemônica da Galaxia. 
No que diz respeito diretamente à visão de Piñeiro, a escolha de Blanco Amor por um modelo literário "importado" de outros povos retira de sua obra a capacidade de uma representação "autêntica" do homem galego.

Somado a isso, Nogueira também aponta uma crítica de Ramón Piñeiro a escolha linguística de Blanco Amor; se para o autor de $A$ Esmorga, a adoção de um galego mais popular está associada a uma tentativa de renovação e ampliação de público leitor, para o outro a língua chega ao nível de uma expressão espiritual e, consequentemente, de alta cultura. Esta questão anda junto com uma diferença da compreensão entre os dois intelectuais do que seria o povo galego, no sentido de seu semelhante. Segundo Nogueira, a opção de Piñeiro, na carta a Fernandez del Riego, por caracterizar a obra de Blanco Amor e seu retrato do povo como "canalla", aponta uma opção pela representação dos galegos em que certos comportamentos não são tolerados.

O que o artigo citado nos permite afirmar é que, seja diante da lógica do regime franquista, seja para uma parcela do próprio meio intelectual galeguista, A Esmorga foi uma obra de ruptura, cujo caráter mais subversivo reside na escolha de Blanco Amor por criticar sistemas hegemônicos como o machismo, o domínio espanhol na Galiza e até mesmo uma visão estetizada e higienizada de povo, língua e cultura. Apesar do aviso inicial do autor, de que se trata de um episódio ocorrido no século XIX, muitas são as evidências de que a Galiza presente na obra persiste, pois muitas das antigas estruturas de coerção e opressão se mantém de pé, mesmo noventa anos depois, tanto no aspecto de violência para com o povo galego, quanto na repressão de sexualidades dissidentes.

A noite de extravagâncias alcóolicas de Cibrán, Bocas e Milhomes, narrada pelo primeiro ao oficial que o interroga, poderia ser lida como a descrição de um episódio de um cruel assassinato a sangue frio, não fosse pelos recursos utilizados pelo autor, como a ironia e carnavalização da narrativa (BLANCO 
apud SANDÉZ, 2009). Além do episódio central, que é a noite de esmorga, são inseridos na narrativa outros dois episódios com caráter de lendas locais, mas que como aponta Xavier Carro (1993), adiantam o desenlace final do romance. No que diz respeito ao episódio que nos interessa neste artigo, o Xardín dos Andrada, diz Carro (1993):

O Bocas queda prendido pola lenda. A partir deste punto, eses personaxes da 'historia' entran a formar parte do mundo dos esmorgantes e convértense en eixe de accións para os tres protagonistas A muller do señor de Andrada vaise converter nunha teima para o Bocas e marcará as iniciativas e as accións desde o intre en que constatan a súa presencia na ventá. (CARRO, 1993, p. 6)

Em concordância com Carro, acreditamos que o episódio em questão não apenas é um conto de valor simbólico, mas também, uma peça essencial no encaixe da obra, primeiro por provocar uma mudança de tom do romance, e segundo por amarrar uma série de elementos ainda um pouco dispersos, que não apenas estão colocados ali como escolha consciente, como interferem diretamente na interpretação do desfecho.

No prefácio de A Esmorga, o autor alerta aos leitores que certamente odiarão Milhomes pelo crime cometido. Entretanto, a navalhada final de Eladio em Bocas é apenas uma de uma série de violências físicas e psicológicas que permeiam o romance, de modo que, ao final, seja possível ler a ironia de Blanco Amor por trás desta afirmação e a subversão dos juízos de valor da Galiza e Espanha à altura de lançamento do romance.

\section{APRESENTAÇÃO DO EPISÓDIO}

No primeiro capítulo, Cibrán, cujo relato dos acontecimentos é a voz narrativa principal, encontra com Juan Fariña e Eladio Vilarchao, conhecidos, respectivamente, pelas alcunhas de Bocas e Milhomes, a caminho do trabalho na construção de uma estrada. Ao contrário de Cibrán, que narra ter passado a noite 
na casa de sua companheira, uma prostituta de nome Raxada, os outros dois dão sinais de terem passado as horas anteriores de esmorga, expressão galega que significa uma noite de exageros, principalmente alcóolicos (mas não exclusivamente, como perceberemos).

Os dois esmorgantes convencem Cibrán a acompanhá-los, especialmente Bocas que, nas palavras do narrador e de si próprio, apresenta uma força de vontade fraca na companhia de Milhomes. O assunto sobre don Fernando de Andrada e sua esposa é introduzido, após as personagens saírem de uma taberna, primeira parada da noite, por Milhomes:

Polo visto, aségun se marmuraba xa facía anos, que eu xa o viña ouvindo dende rapaz, o vinculeiro dos Andradas, que era o único vivo que quedara dunha familia morta toda dunha tísiquis do peito que pegara niles e que os fora levando un a un, pasara toda a mocedade no estranxeiro, a onde o mandaran pra que non se lle apegase o mal. Contábanse dil cousas de moita grandeza, como fan decote os probes cando falan dos ricos, que ó mellor non é tanto... Que si lances de xogo e de amoríos, que si estivera nunha guerra de por eí adiante entre xentes que non teñen ren que vere conosco, que si fora, en segredo, amigo dunha raína, porque disque era baril e bo mozo como non se tiña coñecido outro; que si sabía falar todas as falas do mundo e tal que sei eu...[...] O que parece que era certo é que voltara, xa bastante estragado das súas andadas polo mundo, a facerse cargo de seu herdo que disque que era aínda de moita cuantía. (BLANCO AMOR, 2013, p. 23-24)

Como afirma Cibrán, a história tem ares de uma narrativa aumentada pelas comadres, costureiras e alfaiates que a espalhavam pela cidade (BLANCO AMOR, 2013). Independente disto, o detalhe verídico e de maior interesse é apresentado por último pelo narrador:

Conque disque voltou a viaxar por esas terras de Deus, i ó cabo dos anos chegou de novo traguendo consigo unha dona de tal fermosura, que os poucos que a virán decían que endexamais se tiña ollado cousa somellante...Pro ninguén voltou a ollala dende o día que chegaran, fai desto uns doce anos, que foi cando eu o ouvín contar. Polo visto o Andrada meteu á muller na casa, fechou as portas e non tratou con alma diste mundo nen se lle viu endexemais andar polo pobo, nen xiquera cando veu o rei, nin cando ardeu o bairro da Ferreiría, e iso que o lume andivo a lamberlle as paredes 
do pazo, pola parte que dá a carón da cibdade... (BLANCO AMOR, 2013, p. 24)

Apesar de uma certa resistência de Cibrán, os três acabam concordando em ir até o jardim para ver a bela mulher, que Milhomes afirma já ter vislumbrado uma vez. Já no muro da casa, Bocas sobe nos ombros do narrador e espia por um buraco no muro, até que desce, completamente atônito com o que vira:

- «i Esta eí! », tatexou moi asustado.

- «i Quen, hom?»

- «¿ Non volo decía eu?», argallou o Milhomes, coma pesaroso de que fora certo. «¿Pro víchela ben?»

$-«$ ¿Sandiós, non somella cousa diste mundo! Quedei sen folgos...»

-«Déixate de coñas... Xa che teño vintecatro anos e pasoume o tempo de crer en bruxas».

-«...sandiós!», seguiu a falare, coma se non nos tivese ouvido. «Ponte eí: déixame vela outro pouco».

-«Daquela eu tamén quero ver o que é iso...» (BLANCO AMOR, 2013, p. 29)

Cibrán também vislumbra a dama e concorda com o comentário de Bocas: trata-se de fato de uma belíssima mulher. Apesar disso, o único que irá desenvolver uma obsessão pela esposa de Andrada é Juan Fariña. Após continuarem sua "peregrinação" por diferentes espaços, dentre eles um prostíbulo e uma igreja, Bocas segue falando sobre a mulher, e insiste que retornem ao jardim para vê-la; está obcecado.

Os esmorgantes se dirigem à casa, mais uma vez, e conseguem arrombar uma das portas. Após percorrerem os corredores vazios, eles chegam a encontrar o dono da casa, don Fernando, adormecido em um dos quartos, mas sem sinal da esposa. Neste trecho, porém, chama a atenção de Cibrán o fato do quarto do Andrada ter uma cama de solteiro. Depois da perambulação, eles finalmente encontram a mulher, parada na mesma janela. Bocas vai até ela: 
-«¡Señora...!», díxolle aínda, aventurandóse a collerle unha mau. Pro non ben o fixera, rexeitouna dun pulo coma si se tivese queimado. Co iste movimento o neno caíu ó chau e fíxose cachizos descontra os zulexos do sobrado. $\mathrm{O}$ Bocas, xa reposto, pegou nela pillándoa con bruteza pola añuca, coma si lle fose a bater, e a dona foise pra un costado, inteira, sen se dobregar, cos brazos decote tesos e maus abertas.

-«¡Malia a nai que me pariu! ¡ Grandismo fillo de puta de tolo!», berrou Bocas. E dándolle un tremendo couce á cadeira, guindou coa dona no chau, que alí quedou do mesmo xeito que estaba sentada, cos ollos estantíos brilando co luar. (BLANCO AMOR, 2013, p. 85)

\section{O EPISÓDIO COMO PONTO DE VIRADA NA NARRATIVA DE $A$ ESMORGA}

Como dito anteriormente, o episódio dos Andrada, em suas duas partes a ida ao jardim, seguida do avistamento da bela mulher e depois, a invasão da casa, seguida da descoberta de se trata de uma boneca - é um episódio de importância dentro da narrativa não apenas por sua permanência ao longo do romance - é o único espaço a que as personagens retornam em sua perambulação - mas por outros dois motivos: primeiro, a mudança de tom que acarreta na narrativa, já desde o momento em que os esmorgantes entram na casa; em segundo lugar, por ser não apenas o detonador do comportamento de Bocas que irá desembocar no final trágico, mas pelos temas que levanta a partir da ideia da boneca, e que se relacionam com a personagem de Milhomes e a crítica que Blanco Amor ironicamente constrói desde o prefácio até o fim do romance.

Partindo do primeiro motivo, como aponta Manuel Forcadela em sua obra Guia de lectura de A Esmorga (1991), o romance se constrói a partir da união de duas técnicas narrativas, da descrição de acontecimentos passados - relato de Cibrán -, mas também, das diversas narrativas encaixadas neste relato principal. Estas narrações secundárias apresentam objetivos distintos, seja de apresentar a história das personagens e suas relações, seja como conteúdo metafórico. Como dito por Aléx Alonso Nogueira (2009), citado na introdução deste artigo e 
reiterado por Forcadela (1991), A esmorga busca se inserir em uma tendência artística e cultural do pós-segunda guerra de caráter engajado e alinhado com a esquerda política do Neorrealismo ou Realismo social, cujo produto cultural mais conhecido são provavelmente as pérolas do cinema italiano, mas que também é dotada de uma literatura característica:

\begin{abstract}
A Esmorga de Eduardo Blanco Amor debemos ubicala dentro dos resultados que a perspectiva crítica creada pola socioloxía vai ter no mundo da creación literaria e, fundamentalmente, vencellada a un movemento artístico de posguerra que coñecemos co nome de neo-realismo. $\mathrm{O}$ movemento, como ben pode desprenderse do seu proprio nome, tratáse dun esforzo por encontrar un modo realista de narrar adecuado á expresión dos novos tempos. (FORCADELA, 1991, p. 12)
\end{abstract}

Como afirma o próprio Forcadela (1991), se por um lado o romance parece muito bem inserido neste contexto por sua descrição sem enfeites da realidade, por outro, seria "sectário" caracterizá-la apenas como uma narrativa que se preocupa em retratar uma realidade, de modo que não foram poucos os que já se debruçaram sobre o episódio do Xardín dos Andrada e sua importância como material simbólico dentro da obra, assim como o episódio contado pelo parente de Milhomes sobre a festa dos trabalhadores do Pazo.

Se o segundo também está dentro da narrativa para construir o tecido simbólico da descrição de Blanco Amor sobre a diferença entre a fidalguia galega e seus serviçais, ainda assim não tem a força do episódio dos Andradas, não apenas por se encerrar no momento em que é citado, mas também por não ser determinante no desenrolar dos eventos.

Trazendo mais uma vez a análise de Xavier Carro (1993), a obsessão do Bocas pela mulher, seguida da descoberta de se tratar de uma boneca, tem um tom mítico, ou melhor dizendo, da destruição de uma visão mítica e idealizada de Bocas, que se vê como um herói que invade a casa para salvar a mulher que ali se encontra como prisioneira. 
Apesar de concordarmos com a leitura de Carro (1993), cabe ressaltar que o momento da descoberta da verdadeira natureza da dama não apenas desestabiliza Bocas, acentuando seu comportamento violento, que culmina no estupro de Socorrito, como efetivamente faz com que a narrativa saia de um tom mais irônico, e até cômico em determinados momentos, para uma narração mais densa. O próprio episódio, pela descrição da caminhada das personagens dentro da casa, já estabelece uma atmosfera de medo e apreensão:

Entramos en dous daqueles gabinetes e non se viu persoa diste mundo. Naquela casa polo visto non había ninguén... que pola miña parte até prefería que saíse calquera, fose quen fose, e andar a hostias ou facazos con todos dios, en troques de aquel silencio e de tantos sobrados cheios de cousas ricaces, de mesas postas coma para grandes xantares e de leitos tendiso, largacíos e luxosos, nos que non dormía ninguén, todo con luces acendidas... (BLANCO AMOR, 2013, p. 83)

Embora seja inegável que se trata de uma descoberta chocante, seu poder dentro da narrativa está muito mais no paralelo que estabelece entre o desejo de Bocas por aquele corpo que descobre artificial, e um outro desejo que paira inquietantemente ao longo de toda a narrativa: o desejo por um corpo que não deveria ser desejado.

\section{CORPOS INFAMILIARES, CORPOS IMPRÓPRIOS}

Como apresenta María López Sandéz em seu artigo A Esmorga: espazo urbano e simbolismo espacial (2009), a localização da narrativa na cidade de Ourense, retratada com o nome de Auria nas obras de Blanco Amor, representa um desenvolvimento de uma representação do espaço urbano, já presenta na obra de Vicente Risco e da Xeración Nós (SANDÉZ, 2009); o diferencial consistiria na materialidade que Blanco Amor dá a esse espaço e como ele reforça uma ideia de marginalidade e diferenciação das personagens. A Auria de Blanco Amor não 
é uma idílica Ourense, mas uma cidade marcada por desigualdade social e uma série de enfermidades de corpo e mente. Muito já se escreveu acerca da caracterização da epilepsia na personagem de Cibrán, que chama a questão de saúde de "pensamento" e passa toda a narrativa tentando evitar a chegada de uma nova crise. Entretanto, ele não está isolado no romance: a grande maioria das personagens, principalmente aquelas que são caracterizadas de modo mais pormenorizado, apresentam algum tipo de enfermidade física ou psicológica, ou algum aspecto corporal que destoa de um padrão de corpo saudável. ${ }^{2}$ Padrão este que se faz necessário de delimitar antes de seguir com nossa análise do romance de Blanco Amor.

Na obra Calibã e a bruxa - mulheres, corpo e acumulação primitiva, Silvia Federici (2017) estabelece, nos capítulos, 1, 2 e 3, de que modo o surgimento de um sistema de acumulação de capital, mesmo antes de seu modelo mais desenvolvido, como conheceremos a partir do século XIX, implica em uma necessidade das classes dominantes de forjar uma classe trabalhadora com corpos disciplinados para a venda de mão-de-obra. O que nos últimos duzentos anos se mostrou um ideal bem estabelecido, nos séculos XVI e XVII foi motivo de revolta para grande parte das classes populares e o recrudescimento das execuções e todo tipo de punição para aqueles que não possuíssem um trabalho assalariado. Além disso, baixaram-se uma série de legislações voltadas para o cerceamento da sociabilidade, sexualidade e espaços de lazer:

Proibiram-se os jogos, em particular aqueles que, além de serem inúteis, debilitavam o sentido de responsabilidade do indivíduo e a "ética do trabalho". Fecharam-se tabernas e banhos públicos. Estabeleceram-se castigos para a nudez e também para outras formas "improdutivas"de sexualidade e sociabilidade. Era proibido beber, praguejar e insultar. (FEDERICI, 2017, p. 246)

\footnotetext{
${ }^{2}$ Neste sentido, a relação direta entre a decadência do espaço urbano a partir da decadência física e mental dos indivíduos se assemelha com o retrato de Lisboa realizado por José Cardoso Pires, anos depois em Balada da praia dos cães.
} 
Como ressalta a autora, é importante percebermos que estas modificações significam não apenas uma repressão ao corpo que não trabalha, mas uma sua valorização como uma máquina que gera mercadorias e, consequentemente, riquezas para aquela que a explora:

O corpo então, passou ao primeiro plano das políticas sociais porque aparecia não apenas como uma besta inerte diante dos estímulos do trabalho, mas como um recipiente de força de trabalho, um meio de produção, a máquina de trabalho primária. [...] e o estudo dos movimentos e das propriedades do corpo se converteu no ponto de partida para boa parte da especulação teórica da época - já utilizada por Descartes para afirmar a imortalidade da alma; ou por Hobbes, para investigar as premissas da governabilidade social. (FEDERICI, 2017, p. 249)

Não apenas Federici (2017) coloca Descartes como divisor de águas no sentido de estabelecer uma filosofia que separa corpo e mente. Também Margrit Shildrick (2002) irá ressaltar esse tema nos estudos de Descartes, assim como o privilégio que Descartes dá à mente ao ressaltar que ela não é afetada por perdas de alguma parte do corpo, de modo que este é apenas o simulacro para a mente, não possuindo nenhum tipo de racionalidade, como uma máquina que pode ser facilmente manipulada por algum ser externo.

Se para os contemporâneos de Descartes esta possibilidade de disciplinamento completo dos corpos ainda estava distante, na Galiza do século XIX em que se situa $A$ Esmorga, a valorização do trabalho como medida de valor do ser humano e a associação direta de um corpo não disciplinado para a atividade capitalista, com um caráter duvidoso, já são norma. Ainda no primeiro capítulo, Cibrán ressalta para seu interlocutor o comportamento fora do padrão de Bocas e Milhomes, mesmo que o hábito da esmorga não fosse de sua exclusividade:

Dexáraos na taberna do Narizán, facía dous días, que era sábado, no comenzo dunha daquelas esmorgas que os fixera tan sonados entre todos os esmorguistas de Auria e dos arredores, nas que se metían e non saían até 
quedar guindados por él, coasi decote nun calexón ou nun carreiro das aforas de onde os apañaban os veciños ou os municipás pra botalos é perrera hastra que se lles fose a rolla, ou até que os irmaos fosen pedir por iles, pois os irmaos de entramos a dous, son homes traballadores e de bo siso, que hastra lacha lles daba teren tales perdidos na familia, que non fallan disgracias entre a millor xente... (BLANCO AMOR, 2013, p. 11)

Ao longo da narrativa, não são poucos os momentos em que Cibrán reafirma a imagem de vagabundos que as duas personagens têm na cidade. Entretanto, mesmo com os comentários negativos, ainda existe um diferente nível de aceitabilidade entre Bocas e Milhomes, que parte do próprio narrador. De fato, até saírem da casa dos Andrada, quando o Castizo passa a reprovar mais acentuadamente o comportamento de Bocas, ao longo do romance ele parece ter pena do companheiro, enquanto chega a dirigir verdadeiro desprezo a Milhomes. Mesmo nos trechos em que sua visão parece menos parcial, Cibrán descreve Eladio com estranhamento, como no tão reproduzido trecho em que compara os corpos dos dois homens, acentuando a virilidade, força e masculinidade de Juan Fariña e feminilizando o corpo do outro:

De meio corpo pra embaixo fixera cuns facotexos unha mandileta que o tapaba por diante e que deixaba ó descoberto as nádegas grosas, tremantes e cheias de fochiños coma as dos nenos. Tiña a pele brancuxenta e cheia de mazaduras dos golpes que se diran, e as carnes arrondeadas e seguidas polos bacíos e polas costas coma se fora de manteiga e non tivese tendós como temos os demais homes. No peito, sen migalla de peluxe, abambeábanlle as tetelas cando se movía, leve o demo, coma se fora unha muller. Ó pega veulle un pronto de risa, ó velo eisí, que coidei que afogaba, i eu ferreille, ó pasar, unha chapada no cu que estalou coma un foguete. (BLANCO AMOR, 2013, p. 46)

A comparação com o corpo feminino não se dá apenas pela ausência de pêlos ou pelo movimento de seus mamilos ao se movimentar: Cibrán compara o corpo de Milhomes com o de uma mulher porque, assim como as demais personagens, o considera feminilizado. Não pode ser ignorado o fato de que logo depois deste trecho, em que ele bata nas nádegas de Milhomes, o narrador irá se 
revoltar com um comentário de Eladio acerca de seu pênis. Não se trata de uma questão de hipocrisia: o corpo de Milhomes é um corpo feminino, penetrável, à disposição, principalmente dos corpos masculinos, como o de Cibrán, que não são violáveis ou dignos de qualquer interferência externa, mesmo de uma brincadeira indiscreta.

Em consonância com o que aponta Federici (2017), Margrit Shildrick (2002) afirma que a lógica mecanicista em que Descartes está inserido cria não apenas uma divisão entre corpo e mente, mas um ideal de corpo padrão, baseado no masculino. Entretanto, considerando o quantitativo de corpos que escapam a esse padrão, ele se coloca menos como modelo observável do que como ferramenta disciplinadora e reguladora:

In others words, marked differences in embodiment are seen a priori as deviations from a singular model rather than as equally valid alternatives. [...] in the case of congenital conditions in particular, negative comparison to a putative model of normality seems more a matter of disciplinary regulation and control than of pragmatic value. But what if the focus were on the 'abnormal', on the explicity monstrous? (SHILDRICK, 2002, p. 50)

Shildrick (2002) levanta em seu livro o lugar dos considerados monstruosos, em nossa sociedade. Se talvez o uso de uma teoria voltado para o estudo dos monstros pareça um exagero com relação à personagem de Milhomes, lembremos do que afirmou Cohen (2000, p. 30): “O monstro é a diferença feita carne". Não é monstro que nasce pronto, mas a forma como o seu corpo - e por corpo não nos referimos apenas a características físicas, mas a toda a materialidade das manifestações deste indivíduo no mundo - é lida pela sociedade em que está inserida que leva, não apenas ao lugar que este indivíduo irá ocupar, como também o juízo estabelecido com relação a seu caráter.

A feminilidade de Milhomes o coloca não apenas no mesmo lugar marginal que seus hábitos de esmorgante, mas em um patamar de valor inferior até ao de Bocas que, não apenas também é dado aos excessos, como opta pela 
companhia de Milhomes e, por mais que tente disfarçar, retribui ao desejo do outro. Se o monstro é de fato a diferença feita carne, será seu corpo o principal delator daquilo que o torna o grande marginalizado de uma obra que apresenta personagens com todos os tipos de enfermidades físicas e mentais: sua provável homossexualidade.

\section{A HOMOSSEXUALIDADE COMO MARGINALIDADE}

Como apresenta Alberto Mira (2007) em seu livro De Sodoma a Chueca: una historia cultural de la homosexualidad en España en el siglo XX, a homossexualidade, como é entendida hoje, apesar de sempre ter sido parte da história da humanidade, irá ser caracterizada no século XIX. Dentre os fatores responsáveis por estar marcação temporal, está a prisão de Oscar Wilde, acusado de Sodomia pelo Marquês de Queensberry. As consequências desta prisão são descritas por Mira (2007):

Una vez que el escándalo irrumpe de manera espectacular en la escena pública ya nada será lo mismo... Los juicios de Wilde confirman que la homofobia legal iba en serio y que nadie estaba a salvo. El castigo no se limitaría a prostitutos, chaperos o individuos sorprendidos con las manos en la masa por el exceso de celo de un agente de la autoridad. Ahora se convertía en un asunto de moral pública. El entramado conceptual que se había construido en torno a la categoría de homosexualidad adquiere gran vitalidad, la maquinaria homofóbica se pone en marcha, la homosexualidad abandona los discursos especializados y se convierte en un tema público. (MIRA, 2007, p. 63)

A condenação de Oscar Wilde ressoa mais por estabelecer uma legitimidade para uma homofobia legal do que por estabelecer uma caracterização do homossexual. Mais do que um marco do que define um homem homossexual, além do desejo afetivo e sexual por outro homem, é a demarcação 
de que não apenas esse desejo é condenado culturalmente, mas pode ser passível de punição legal.

Não por acaso, Mira (2007) irá apontar que das três linhas de posições principais acerca da homossexualidade, presentes na Espanha, a primeira a se manifestar e contemporânea ao julgamento de Wilde é a da homossexualidade em posição marginal.

Entretanto, como o próprio Mira (2007) afirma, é importante ter em conta que a diferenciação do homossexual não se realizar pela própria categoria, mas por um discurso normativo em torno da experiência sexual em que, assim como o padrão de corpo apresentado por Shildrick (2002), mais do que ser um grupo no qual se inserem aqueles que se identificam com suas delimitações, exclui os que nelas não se encaixam.

No caso de A Esmorga, falar de um padrão de homossexualidade marginal é apontar não somente uma representação em que Milhomes está a margem por seu comportamento e corpo, mas também porque ao longo da narrativa lhe são associados alguns comportamentos criminosos, até o crime final, que é o assassinato de Bocas. Como mencionado na seção anterior, Blanco Amor já nos adverte deste fato no prefácio: “Tamén tiven que me valer do Tijeradeoro, que era un xastre, fillo doutro xastre, compañeiro de agulla do Milhomes, a quen o leitor coñecerá de contado e colleralle - supoño eu, que neso hai difrenza de gostos - xenreira pra toda a vida." (BLANCO AMOR, 2013, p. 2).

A hostilidade que Blanco Amor prevê para com Milhomes, se por um lado, se justifica pelo fato de ser ele o assassino de Bocas, além de todas as caraterizações negativas da parte de Cibrán, por outro, parece desproporcional se analisarmos que atitudes semelhantes são tomadas por Bocas: os pequenos roubos, o abuso de álcool e mesmo as agressões físicas dirigidas a terceiros não são exclusividade de Eladio, Na realidade, se voltarmos à cena do estupro de 
Socorrito, perceberemos que a atitude não é aceita por Cibrán ao narrá-la, apesar de não tentar impedir a violência até que ouça os gritos da mulher:

Eu non podía co meu desacougo porque si consentía o que se me estaba a figurar ía a tere un cargo de concencia xa para toda miña vida. Sabíase dabondo, por outros covardes e larchás que xa tencionaran aquelo mesmo, que a Socorrito era moi forte e valente, capacete de se defendere dos aldraxes. E, por outra parte, coma tiña ben conecido a aquil animal, fóra a ialma que Deus puxo nil tan mal empregada, deprocatábame ben que si lle marraba o enxeño de terse botado a iauga de olor pra arrecender a señorito, era home pra facere calisquera cousa desaxeitada. (BLANCO AMOR, 2013, p. 97-98)

A violência de Milhomes, neste sentido, se mostra menos injustificável que a de Bocas, tendo em vista que este se decide por possuir uma mulher de qualquer maneira, independentemente de sua vontade, após a descoberta da boneca, enquanto que a atitude de Milhomes, embora condenável, é uma retaliação ao estupro. Nosso objetivo aqui não é elencar qual violência é mais ou menos condenável, mas apontar que existe uma distância entre a afirmação do autor de uma determinada personagem ser o provável foco da hostilidade do leitor, ao mesmo tempo em que outras personagens apresentam motivos para tal.

Voltando à questão do desejo, dentro desta mesma esfera são dados exemplos de relacionamentos tradicionalmente condenáveis, em maior ou menor escala, desde a relação de Cibrán com uma prostituta, afirmada por todos e principalmente por ele, que não nega o afeto por Raxada, até don Fernando, que é casado com uma boneca. Cabe nos perguntar porque, dentro de uma narrativa com tipos tão complexos, Blanco Amor não apenas reforça a marginalidade das personagens homossexuais, como abre seu romance orientando os afetos do leitor.

Para chegar nesta questão, voltemos, mais uma vez, ao episódio dos Andrada, mais especificamente, ao desenlace deste episódio: 


\section{ENTRE CORPOS PRÓPRIOS E IMPRÓPRIOS PARA O DESEJO}

No momento em que as personagens retornam à casa dos Andrada, a narrativa já desenvolveu o suficiente não apenas em termos de acontecimentos, mas principalmente de apresentação das personagens. À esta altura temos consciência de que Milhomes nutre um desejo por Bocas, que não é explicitamente correspondido, mas também não é rejeitado de todo, já que o próprio Juan afirmar não conseguir se separar de Eladio. Apesar disso, se o segundo apresenta um comportamento considerado feminino e não parece manifestar desejo sexual ou afetivo por mulheres, Bocas tem um relacionamento com uma prostituta, Lola, a Viguesa, que dá sinais de inclusive estar apaixonada por ele, sem contar os diversos momentos em que afirma que quer se deitar com uma mulher, sendo o alvo maior de sua obsessão a esposa de don Fernando, motivo pelo qual voltam à casa.

Neste ponto, cabe analisar que, apesar da personagem tentar fazer sexo (e violentamente conseguir) com outras mulheres ao longo da narrativa, a forma como Bocas reage à boneca é distinta da postura que apresenta para Lola e Socorrita. No caso da prostituta e da morada do Campos das Bestas, a procura pelo sexo parece menos motivada por um desejo e/ou obsessão e mais pela necessidade de exercer uma postura sexual de macho. Mesmo com Lola, com quem Bocas mantém relações sexuais com regularidade, ela dá mais mostras de interesse do que ele. Tendo isso em mente, é possível levantar a hipótese de que, além da boneca, apenas outra personagem dentro da obra desperta o desejo de Bocas, mesmo que reprimido: Milhomes.

Apesar de, naturalmente, existir uma diferença considerável entre desejar um outro ser humano e desejar um objeto inanimado, da mesma forma que Bocas nega que o elo que o mantém atado a Eladio é o do desejo, no momento em que percebe que a bela mulher é uma boneca, Juan xinga don Fernando ("Grandismo 
fillo de puta de tolo!") (BLANCO AMOR, 2013, p. 85) e reconhece a ilegitimidade de seu desejo.

Considerando o desenrolar dos fatos após este trecho, é possível levantarmos a hipótese de que o episódio do Xardín dos Andrada não apenas desestabiliza Bocas e permite assim a exacerbação de uma masculinidade violenta: ela estabelece um paralelo entre o desejo ilegítimo de don Fernando pelo corpo impróprio da boneca, com o desejo de Bocas por Milhomes, não apenas para o leitor, mas para a própria personagem de Juan Fariña, que encontra na relação sexual com uma mulher, uma forma de negá-lo.

O que cria um desfecho ainda mais perturbador do que este episódio é o fato de que não apenas Bocas chega ao final disposto a eliminar seu desejo: também Milhomes o faz. Neste sentido, nos permitimos discordar das análises que enxergam no assassinato final um crime de ciúmes; Milhomes de fato sente ciúmes por Bocas, mas este se manifesta principalmente nos momentos em que Bocas está com Lola no prostíbulo e em sua fascinação pela dona Andrada. O que motiva Milhomes a assassinar Bocas é a revolta diante da barbárie do estupro e, principalmente, uma revolta diante daquilo que, para ele é monstruoso: a faceta de masculinidade mais violenta e agressiva de Bocas.

\section{CONSIDERAÇÕES FINAIS}

Apesar de inicialmente ter despertado certa resistência por parte do setor hegemônico do Editorial Galaxia nos anos cinquenta do século XX, A Esmorga é hoje, inegavelmente, um divisor de águas na literatura galega. Eduardo Blanco Amor não apenas confirma seu talento como prosador, como cria uma linguagem que, ao mesmo tempo que leva o leitor ao dia-a-dia da língua em uma das principais cidades da Galiza, também é fruto dos anos de trabalho pela cultura e idioma no exílio. Desse modo, de diferentes maneiras, a história de Cibrán, Bocas 
e Milhomes é um retrato de elementos já estabelecidos, mas também de subversão destes mesmos elementos dentro dos limites que estes fixam.

Se a representação de duas personagens homossexuais se faz dentro de um perfil que associa à homossexualidade à marginalidade da sociedade e da lei, por outro lado, utiliza estes limites impostos para apontar a homofobia do próprio leitor, ao direcionar sua hostilidade para uma personagem que não é mais agressiva ou violenta do que as demais.

O episódio do Xardín dos Andrade é então, ponto importante de virada na narrativa ao obrigar não apenas os leitores a se confrontar com a natureza criminosa e perturbada das personagens, desde um Cibrán conivente com as infrações dos dois esmorgantes até don Fernando e seu casamento com um ser inanimado, mas o próprio Bocas com seus desejos que considera impróprios e cuja incapacidade de lidar leva ao trágico final para o trio de protagonistas.

As personagens de $A$ Esmorga, cada qual a sua maneira, são verossímeis na mesma medida em que se apresentam como reprováveis e nos provocam o desejo de distanciá-los de nossa própria experiência. Entretanto, como afirma Shildrick (2002), a importância dos monstros se coloca justamente em sua ambiguidade: é justamente quando acreditamos que eles são mais monstruosos, que estão mais próximos natureza humana.

\section{REFERÊNCIAS}

BLANCO AMOR, Eduardo. A esmorga. 14ª ed. Vigo: Galaxia, 1995

CARRO, Xavier. Claves para unha lectura de A esmorga. Grial. Vigo, v. 31, n. 117, p. 517, jan./mar. 1993.

COHEN, Jeffrey Jerome. Cultura de Monstro: sete teses. In: HUNTER, Ian; DONALD, James; COHEN, Jeffrey Jerome; GIL, José. A pedagogia dos monstros: os prazeres e os perigos da confusão de fronteiras. Belo Horizonte: Autêntica, 2000. p. 25-55.

FEDERICI, Silvia. Calibã e a bruxa: mulheres, corpo e acumulação primitiva. Tradução por Coletivo Sycorax. São Paulo: Elefante, 2017. 
FORCADELA, Manuel. Guía de lectura de A esmorga de Eduardo Blanco Amor. Vigo, 1991. Disponível em: [https://oximnasiodeacaderno.files.wordpress.com/2012/05/guc3ada-delectura-de-a-esmorga-de-eduardo-blanco-amor.pdf]. Acesso em:

NOGUEIRA, Álex Alonso. Blanco Amor e a constitución do campo literario galego durante os anos de Galaxia. Grial. Vigo, v. 47, n.184, p. 28-35, out./dez. 2009.

PIRES, José Cardoso. Balada da praia dos cães: dissertação sobre um crime. Rio de Janeiro: Civilização Brasileira, 1983.

SANDÉZ, María López. A esmorga: espazo urbano e simbolismo espacial. Grial. Vigo, v. 47, n. 184, p. 16-27, out./dez. 2009.

Nota do editor:

Artigo submetido para avaliação em: 31 de março de 2021.

Aprovado em sistema duplo cego em: 19 de setembro de 2021. 